\title{
The Correlation between Gross Motor Function Classification System and Spasticity in Children with Cerebral Palsy
}

\author{
${ }^{1}$ Ika Rosdiana*, ${ }^{2}$ Ariestiani \\ ${ }^{1}$ Department of Medical Rehabilitation, Medical Faculty, Universitas Islam Sultan Agung, Semarang, \\ Indonesia \\ ${ }^{2}$ Medical Faculty, Universitas Islam Sultan Agung, Semarang, Indonesia \\ *Corresponding Author \\ Jl Raya Kaligawe Km4 Semarang/(024)6583584 \\ Email: ikadrkfr@unissula.ac.id
}

Received:

17 August 2021
Revised:

13 December 2021
Accepted:

21 December 2021
Published:

31 December 2021

\begin{abstract}
Gross Motor Function Classification System (GMFCS) was used as a criterion to classify motor function in children with cerebral palsy. Spasticity is an increase in muscle resistance to passive stretching, which is an involuntary muscle activity associated with upper motor neuron paralysis that occurs in CP children so that it interferes with their activities. The purpose of this study was to determine the relationship between GMFCS and the level of spasticity assessed by the Ashworth scale in children with cerebral palsy. The analytical research method was observational with a cross sectional approach, the independent variable was assessed on the functional scale using the GMFCS and the dependent variable was assessed for spasticity using the Ashworth scale. The research sample was CP children at YPAC Semarang city. The results of this study are that the highest GMFCS level in children with cerebral palsy at SLB YPAC Semarang City is level III and IV as much as $25.0 \%$ while the assessment of spasticity using the ashworth scale obtained ashworth level 3 as much as $58.3 \%$ while the results of the calculation of the non-parametric Spearman correlation test were obtained. $\mathrm{p}$ value $=0.000(\mathrm{p}<0.05)$ with a value of $\mathrm{r}=0.837$. Therefore, it can be concluded that there is a positive correlation between GMFCS and the level of spasticity assessed using the Ashworth scale in children with cerebral palsy.
\end{abstract}

Keywords: Ashworth Cerebral Palsy; GMFCS; Spasticity

\section{INTRODUCTION}

Cerebral palsy (CP) describes a group of permanent disorders of movement and posture development, causing activity limitations that are associated with non-progressive disorders that occur in the fetus or the developing baby's brain. The motor disorders of cerebral palsy are often accompanied by disturbances of sensation, perception, cognition, communication, and behavior caused by epilepsy and other musculoskeletal problems. Studies from various countries on the prevalence of cerebral palsy occur as much as $1.5-2.7$ per 1000 children. Incidence is usually calculated as the number of children with cerebral palsy in a given area divided by the number of neonates who survived in that area. Variations in the frequency of CP between studies aimed at several factors, including the aim to measure the severity of disability (the life style assessment score) including population studies in children with developmental disorders, children with mild spectrum GMFCS I were not included in the study (Eunson, 2012).

Spasticity is the occurrence of increased muscle tone and reduced muscle strength (weakness) are the main disorders associated with people with CP. The primary goal of most 
interventions is to improve function but associations between flexibility and function or between strength and function have rarely been reported in the same group of people with CP. Historically, spasticity was considered a major disorder of people with CP. Therefore if the spasticity is reduced, the function is automatically increased (Ross \& Engsberg, 2007). There are many assumptions about the relationship between flexibility, strength, and function in people with CP. Spasticity is considered to be inversely proportional to gross motor function and gait, so the greater the spasticity the lower the level of function. Hamstring spasticity has been associated with a flexed knee gait pattern and plantarflexors spasticity has been associated with a gait pattern (Ross \& Engsberg, 2007). Contractures occur when there is loss of joint motion due to structural changes in the muscles, ligaments, and tendons surrounding the joint due to spasticity. Nevertheless, spasticity is beneficial for children with cerebral palsy. Increased tone is useful for children which will help keep the legs straight, thereby supporting the child's weight against gravity so that by increasing the tone of the extensors of the torso will help the child to be able to stand and step. Spasticity will also help maintain muscle mass and bone density (Reilly et al., 2020).

Gross Motor Function Classification System (GMFCS) was used as a criterion to classify motor function in children with cerebral palsy. GMFCS for cerebral palsy is based on movements that children with cerebral palsy can perform alone, especially for sitting, moving, and mobility. The GMFCS consists of five levels that are meaningful in everyday life. Level differences are based on functional limitations, the need for hand-held mobility aids crutches, canes, walkers or wheelchairs to a much lesser extent. Determination of each level is assessed based on mobility after the age of 6 years. Manifestations of gross motor function depend on age, especially during infancy and early childhood. For each level, it is described separately in several age ranges. For children aged 6 to 12 years and 12 to 18 years, the age range reflects the potential impact of environmental factors (eg distance in school and community) and personal factors. (Rethlefsen et al., 2017). GMFCS is a method to describe gross motor function, based on the use of mobility aids and exercises while sitting, standing, and walking. It is intended to classify the level of gross motor function of patients according to their maximum ability. (Palisano et al., 2007).

Improving children's daily life skills is a fundamental goal of rehabilitation strategies, knowledge of the relationship between motor disorders and activity limitations is essential for clinical practice. The 2001 WHO International Classification of Functioning, health and disability defines the disorder as a problem in body structure and activity limitations resulting in difficulty in activities and limited participation. Although spasticity is related to the level of activity limitation, there are findings that support the hypothesis that spasticity contributes to GMFCScompliant activity limitations that occur in children with cerebral palsy where motor function itself will be impaired by weakness, lack of selective motor control, balance problems, and perceptual difficulties (Katusic \& Alimovic, 2013). Nonetheless, many rehabilitation interventions focus on reducing spasticity with the assumption that reducing spasticity will lead to improved motor skills. Therefore, knowledge of the relationship between spasticity and motor function is particularly meaningful in clinical work where spasticity has been considered a major disorder of bodily function, such as in spastic cerebral palsy.

The purpose of this study was to determine the relationship between GMFCS and the level of spasticity in children with cerebral palsy aged 6-12 years and to determine the average level of spasticity and the average GMFCS in children with cerebral palsy at YPAC Semarang City.

\section{METHOD}

The type of this research is an analytic observational study with a cross sectional approach. The independent variable is the functional scale of the GMFCS Cerebral Palsy child and the dependent variable is the level of spasticity with the Ashworth scale. The data were analyzed by bivariate 
correlation analysis using the spearman test because the instrument's measurement scale is ordinal. The instrument used in this study is the Gross Motor Function Classification System to assess the functional activity of children with Cerebral Palsy consisting of levels I, II, III, IV, and $\mathrm{V}$ and the Ashworth Scale to assess the degree of spasticity in children with Cerebral Palsy consisting of 5 levels, namely Ashworth 0, 1, 2, 3, and 4.

Table 1. Gross Motor Function Classification System

\begin{tabular}{ll}
\hline GMFCS I & $\begin{array}{l}\text { Children can walk at home, at school, outdoors and in the community. They can } \\
\text { climb stairs without holding on. They are able to perform gross motor skills such } \\
\text { as running and jumping, but limited speed, balance and coordination. }\end{array}$ \\
\hline GMFCS II & $\begin{array}{l}\text { Children can walk and climb stairs holding on. They have difficulty walking long } \\
\text { distances and maintaining balance on uneven surfaces and inclines. They can } \\
\text { walk with little assistive devices or hold on to objects around them. They have } \\
\text { only minimal skills when it comes to gross motor skills such as running and } \\
\text { jumping. }\end{array}$ \\
\hline GMFCS III & $\begin{array}{l}\text { Children walk using mobility aids (walkers). They are still possible to climb } \\
\text { stairs by hand with supervision or help from others. For long distances, they can } \\
\text { use a wheelchair, while for short distances they can use a wheeled walker. }\end{array}$ \\
\hline GMFCS IV & $\begin{array}{l}\text { Children use mobility aids with the help of others. They can walk short distances } \\
\text { at home with a walker with the help of another person. At school, outside the } \\
\text { home and in the community they use a wheelchair with the help of others. }\end{array}$ \\
\hline GMFCS V & $\begin{array}{l}\text { Children do mobility using a wheelchair with the help of another person. They } \\
\text { have limited ability to maintain antigravity body and torso posture and control } \\
\text { leg and arm movements. }\end{array}$ \\
\hline
\end{tabular}

Table 2. Ashworth Scale Results

\begin{tabular}{ll}
\hline Ashworth 0 & No increase in muscle tone \\
\hline Ashworth 1 & Slight increase in muscle tone \\
\hline Ashworth 2 & There is an increase in muscle tone but can still be flexed \\
\hline Ashworth 3 & Increased muscle tone, passive movement is difficult \\
\hline Ashworth 4 & Increase in muscle tone and start contractures \\
\hline
\end{tabular}

After completing the licensing and ethical clearance this research was carried out at YPAC Semarang City by 5th semester students of the Unissula Medical Faculty who had received previous training, before carrying out the research the researcher explained what would be studied by giving informed consent to the patient's parents, the study was carried out in October November 2019 with ethical clearance number: 657/X/2019/Unissula Medical Faculty Bioethics Commission. The research sample was children with cerebral palsy who met the inclusion criteria, namely suffering from cerebral palsy, aged 6-12 years, undergoing a therapy program for at least 1 year while children who were post-seizure due to epilepsy were excluded, the sample size was taken based on consecutive sampling so that 24 children were obtained cerebral palsy during October - November 2019. 


\section{RESULTS AND DISCUSSION}

From the research results obtained data characteristics in Table 3.

Table 3. Characteristics of Research Subjects

\begin{tabular}{lcc}
\hline Characteristics & $\begin{array}{c}\text { N } \\
\text { (Total) }\end{array}$ & $\begin{array}{c}\text { Percentage } \\
(\%)\end{array}$ \\
\hline Age & 8 & 33.3 \\
\hline 7 & 2 & 8.3 \\
\hline 8 & 3 & 12.5 \\
\hline 9 & 4 & 16.6 \\
\hline 10 & 3 & 12.5 \\
\hline 11 & 4 & 16.6 \\
\hline 12 & & \\
\hline Sex & 11 & 45.8 \\
\hline Goy & 13 & 54.2 \\
\hline Cerebral Palsy Type & & \\
\hline Spastic Hemiplegy & 1 & 4.1 \\
\hline Spastic Diplegia & 11 & 45.8 \\
\hline Spastic Triplegy & 1 & 4.1 \\
\hline Spastic Quadriplegia & 8 & 33.3 \\
\hline Ataxia & 1 & 4.1 \\
\hline Athetoid Ataxia & 1 & 4.1 \\
\hline Spastic Diplegic Athetoid & 1 & 4.1 \\
\hline
\end{tabular}

In table 3, it can be seen that the majority of the subjects in this study were 7 years old, with 8 children $(33.3 \%)$, more females than males, and the highest number of spastic diplegic types of cerebral palsy compared to other types (45.8\%).

Table 4. Level Distribution of GMFCS

\begin{tabular}{|c|c|c|}
\hline Level of GMFCS & N (Total) & Persentase (\%) \\
\hline level I & 4 & $16,7 \%$ \\
\hline level II & 4 & $16,7 \%$ \\
\hline level III & 6 & $25,0 \%$ \\
\hline level IV & 6 & $25,0 \%$ \\
\hline level V & 4 & $16,7 \%$ \\
\hline Total & 24 & $100 \%$ \\
\hline
\end{tabular}

Table 4 shows that the highest GMFCS level in children with cerebral palsy at YPAC Semarang City is at levels III and IV at 25.0. Level III means that children walk using handheld mobility aids. Transferring from sitting to standing requires the physical assistance of another person. When traveling long distances, children use mobility aids with wheels. Level IV means that children use mobility aids that require the assistance of others. Children need adaptive seating for torso and hip control and physical assistance for most transfers. At home, children use floor mobility (roll, creep, or crawl), walk short distances with physical assistance, or use wheelchair mobility. At school, outside the home, and in the community, children are encouraged to use a wheelchair. 
Table 5. The Distribution of Ashworth

\begin{tabular}{ccc}
\hline Skala Ashworth & N (jumlah) & Persentase (\%) \\
\hline Ashworth 0 & 0 & $0 \%$ \\
Ashworth 1 & 4 & $16,7 \%$ \\
Ashworth 2 & 14 & $58,3 \%$ \\
Ashworth 3 & 3 & $12,5 \%$ \\
Ashworth 4 & 3 & $12,5 \%$ \\
\hline Total & $\mathbf{2 4}$ & $\mathbf{1 0 0 \%}$
\end{tabular}

Table 5 shows that the most ashworth scale in children with cerebral palsy at YPAC Semarang City has an ashworth scale of $58.3 \%$ which means that most of the increase in muscle tone is indicated by the presence of resistance when passive movements are carried out in the knee joint and none of the children children who do not have spasticity/ashworth 0 .

Table 6. Frequency distribution between GMFCS and Ashworth

\begin{tabular}{ccccccc}
\hline \multirow{5}{*}{ Ashworth } & & \multicolumn{5}{c}{ GMFCS } \\
\hline \multirow{5}{*}{} & & I & II & III & IV & V \\
\cline { 2 - 7 } & 0 & 0 & 0 & 0 & 0 & 0 \\
\cline { 2 - 7 } & 1 & 3 & 1 & 0 & 0 & 0 \\
\cline { 2 - 7 } & 2 & 0 & 0 & 0 & 2 & 1 \\
\cline { 2 - 7 } & 4 & 0 & 0 & 0 & 0 & 3 \\
\hline
\end{tabular}

Table 6 shows that the majority of children with ashworth 2 have GMFCS III level, which is $25 \%$ and $12.5 \%$ of children with ashworth 4 have GMFCS V.

Table 7. Correlation of GMFCS with Ashworth scale

\begin{tabular}{ccc}
\hline & $\operatorname{Sig}(\mathrm{p})$ & Koeff correlation $(\mathrm{r})$ \\
\hline Ashworth-GMFCS & $0,000^{*}$ & $0,837^{*}$ \\
\hline *Spearman-rho test - Bivariate correlation analysis using spearman test
\end{tabular}

Based on the data in table 7, the results of the calculation of the non-parametric Spearman correlation test obtained a sig value of $0.000(p<0.05)$ with a value of $r=0.837$ which means that there is a positive correlation between GMFCS and the Ashworth scale in patients with cerebral palsy.

The GMFCS level predicts a change in all domains except the cognition domain of 4-26\% variance. This shows that the level of GMFCS reflects not only the severity of motor impairment in Cerebral Palsy but also the degree of brain damage. Furthermore, significant correlations were revealed between the severity of motor impairment and developmental function, and between developmental function itself. Significant and complex correlations were observed between developmental functioning in children with Cerebral Palsy eg manual abilities related to self-care skills. Previous studies revealed that GMFCS levels were not only correlated with gross and fine motor function, but also with self-care function in children with Cerebral Palsy (Chen et al., 2011). Shevell et al (2009) in their study found that there was a very strong relationship between neurological subtypes and the level of GMFCS. Accurate determination of the neurological subtype remains an important element of the evaluation of a child with cerebral palsy. Although this subtype is permanent and does not change, the profile for children with Cerebral Palsy should be assessed based on these functional and motor subtypes, which can then inform the individual concerned, family, medical, and rehabilitation. Accurate and well-informed pathways are a 
necessary prerequisite for achieving optimal outcomes that facilitate broad participation for affected children.

The cohort study conducted by Fosdahl (2020) on Cerebral Palsy children showed that there was an increase in Popliteal Angle (PA) based on age at GMFCS levels I, II and III. Popliteal angle is identical to the degree of spasticity, PA between GMFCS levels are significantly different. However, at the age of 14 years no significant difference was found. Hamstring spasticity increased rapidly during the children's first 4 years at all GMFCS levels, but the degree of spasticity differed significantly between groups. The highest spasticity occurred around the age of 6 years, the incidence of seizures decreased in GMFCS level III, but at GMFCS levels I and II the spasticity continued to increase. The results of this study have implications for clinical decision making, that Poplitea Angle and hamstring spasticity will continue to increase in adolescence, especially at GMFCS levels I and II, therefore the management of hamstring spasticity should be prioritized from an early age.

Dehno et al (2012) stated in their research that there was no relationship between spasticity and the level of GMFCS on Quality of Life, this happened because they had adapted to their condition and accepted the condition of disability so that it did not affect their quality of life. The study showed that although muscle stiffness/spasticity and seizures were common disorders in Cerebral Palsy patients, they did not affect the quality of life of people with Cerebral Palsy. In addition, the limitations of gross motor function as assessed using the GMFCS also did not affect the quality of life in people with Cerebral Palsy.

Gorter et al (2009) in their research found that spasticity is a small part of the factors causing the development of gross motor function disorders in children with Cerebral Palsy, another influencing factor is the environment and family that determine the gross motor development of a child with Cerebral Palsy. Only $8 \%$ influence of spasticity on gross motor function in children with Cerebral Palsy. The study revealed that spasticity in early life is a minimal factor in motor functional change apart from environmental and family factors. Knowledge of the determinants of gross motor performance is expected to be useful for setting realistic rehabilitation goals in reducing spasticity and improving gross motor function. Whereas based on the study of Alriksson-Schmidt and Hägglund (2016), GMFCS is designed to classify gross motor function in children and adolescents with Cerebral Palsy regardless of the type of Cerebral Palsy. However, some children with Cerebral Palsy are difficult to classify in certain levels of GMFCS. GMFCS is a classification system and is not intended for training tools to achieve an increase in gross motor function from lower to higher. GMFCS is a level of gross motor function that will continue over time and is associated with comorbidities and interventions.

In the research of Mutlu et al (2008), the Intraclass Correlation Coefficient (ICC) score did not find a difference between the Ashworth Scale and the Modified Ashworth Scale. The results obtained that the reliability of this measuring instrument is quite high from its reliability. This asserts that this scale must be interpreted by the same rater in deciding the size of the scale to obtain valid results. Likewise, a study conducted by Ansari (2006) showed that when the Ashworth Scale and Modified Ashworth Scale were used in standard procedures and in clinical situations the results would be less good if the assessors were not given training beforehand. There is no significant difference between the two scales. In this study the Ashworth Scale assessment was carried out by the same assessor and had received previous training.

Management of spasticity in children with Cerebral Palsy is very complex and is a challenge for the treatment team. Because spasticity interferes with function, causes deformity and causes pain. Treatment using chemical drugs and surgery should be evidence-based and depend on the degree of functional impairment resulting from the spasticity and its location. The therapies that are often used are botulinum toxin, intrathecal baclofen, surgical interventions such as selective rhizotomy and orthopedic surgery (Reilly et al., 2020). 


\section{CONCLUSION}

From the results of this study, it was found that there is a strong relationship between GMFCS and the level of spasticity in cerebral palsy children aged 6-12 years at YPAC, which means that the higher the Ashworth value, the higher the GMFCS level. Thus, it is necessary to intervene against spasticity to increase the mobility of children with Cerebral Palsy. It is suggested that further research should be carried out according to the type of CP and analysis of other factors as comorbidities in children with Cerebral Palsy.

\section{ACKNOWLEDGMENT}

Thank you to all respondents and their parents who have been a part of this research. Thank you to the management of YPAC Semarang and the Dean of the Medical Faculty, Universitas Islam Sultan Agung who have supported and facilitated the implementation of this research.

\section{REFERENCES}

Alriksson-Schmidt, A., \& Hägglund, G. (2016). Pain in Children and Adolescents with Cerebral Palsy: A Population-Based Registry Study. Acta Paediatrica, International Journal of Paediatrics 105(6): 665-70.

Ansari, N. N., Soofia Naghdi, Hoda Moammeri, \& Shohreh Jalaie. (2006). Ashworth Scales Are Unreliable for the Assessment of Muscle Spasticity. Physiotherapy Theory and Practice 22(3): 119-25.

Chen, Chia Ling. (2011). Developmental Profiles and Temperament Patterns in Children with Spastic Cerebral Palsy: Relationships with Subtypes and Severity. Journal of the Formosan Medical Association 110(8): 527-36. http://dx.doi.org/10.1016/S0929-6646(11)60079-X.

Dehno, N. S., Shohreh Noorizadeh Dehkordi, Mehdi Dadgoo, \& Masoud Salehi. (2012). Association between Spasticity and the Level of Motor Function with Quality of Life in Community Dwelling Iranian Young Adults with Spastic Cerebral Palsy. Medical Journal of the Islamic Republic of Iran 26(4): 150-56.

Eunson, P. (2012). Aetiology and Epidemiology of Cerebral Palsy. Paediatrics and Child Health (United Kingdom) 22(9): 361-66. http://dx.doi.org/10.1016/j.paed.2012.05.008.

Fosdahl, Merete Aarsland, Reidun Jahnsen, Are Hugo Pripp, and Inger Holm. (2020). Change in Popliteal Angle and Hamstrings Spasticity during Childhood in Ambulant Children with Spastic Bilateral Cerebral Palsy. A Register-Based Cohort Study.” BMC Pediatrics 20(1): $1-9$.

Gorter, Jan Willem, Olaf Verschuren, Laura Van Riel, \& Marjolijn Ketelaar. (2009). The Relationship between Spasticity in Young Children (18 Months of Age) with Cerebral Palsy and Their Gross Motor Function Development. BMC Musculoskeletal Disorders 10(1): 19.

Katusic, Ana, \& Sonja Alimovic. (2013). The Relationship between Spasticity and Gross Motor Capability in Nonambulatory Children with Spastic Cerebral Palsy. International Journal of Rehabilitation Research 36(3): 205-10.

Mutlu, Akmer, Ayse Livanelioglu, and Mintaze Kerem Gunel. (2008). Reliability of Ashworth and Modified Ashworth Scales in Children with Spastic Cerebral Palsy. BMC 
Musculoskeletal Disorders 9: 1-8.

Palisano, R., Rosenbaum, P., Bartlett, D., Livingston, M., Walter, S., Russell, D., ... Galuppi, B. (2007). Gross Motor Function Classification System Expanded and Revised. Dev Med Child Neurol, 39, 214-223. https://doi.org/10.1111/j.1469-8749.2."

Reilly, M., Kayley Liuzzo, \& Allison B. Blackmer. (2020). Pharmacological Management of Spasticity in Children With Cerebral Palsy. Journal of Pediatric Health Care 34(5): 495509.

Rethlefsen, S. A. (2017). Prevalence of Specific Gait Abnormalities in Children with Cerebral Palsy Revisited: Influence of Age, Prior Surgery, and Gross Motor Function Classification System Level." Developmental Medicine and Child Neurology 59(1): 79-88.

Ross, S. A., \& Jack R. Engsberg. (2007). Relationships Between Spasticity, Strength, Gait, and the GMFM-66 in Persons With Spastic Diplegia Cerebral Palsy. Archives of Physical Medicine and Rehabilitation 88(9): 1114-20.

Shevell, M. I., Lynn Dagenais, \& Nicholas Hall. (2009). Comorbidities in Cerebral Palsy and Their Relationship to Neurologic Subtype and GMFCS Level. Neurology 72(24): 2090-96. 